\title{
Aquifex aeolicus 3-Deoxy-D-manno-2-Octulosonic Acid 8-Phosphate Synthase: A New Class of KDO 8-P Synthase?
}

\author{
Matthew R. Birck, Ronald W. Woodard \\ Department of Medicinal Chemistry, College of Pharmacy, University of Michigan, 428 Church Street, Ann Arbor, MI 48109-1065, USA \\ Received: 15 June 2000 / Accepted: 6 October 2000
}

\begin{abstract}
The relationship between 3-deoxy-D-manno2-octulosonic acid 8-phosphate (KDO 8-P) synthase and 3-deoxy-D-arabino-2-heptulosonic acid 7-phosphate (DAH 7-P) synthase has not been adequately addressed in the literature. Based on recent reports of a metal requiring $\mathrm{KDO}$ 8-P synthase and the newly solved X-ray crystal structures of both Escherichia coli KDO 8-P synthase and DAH 7-P synthase, we begin to address the evolutionary kinship between these catalytically similar enzymes. Using a maximum likelihood-based grouping of $29 \mathrm{KDO} 8$-P synthase sequences, we demonstrate the existence of a new class of KDO 8-P synthase, the members of which we propose to require a metal cofactor for catalysis. Similarly, we hypothesize a class of DAH 7-P synthase that does not have the metal requirement of the heretofore model E. coli enzyme. Based on this information and a careful investigation of the reported X-ray crystal structures, we also propose that KDO 8-P synthase and DAH 7-P synthase are the product of a divergent evolutionary process from a common ancestor.
\end{abstract}

Key words: Lipopolysaccharide - O-antigen - Shikimate pathway - Maximum likelihood

\section{Introduction}

Many comparisons have been made between Escherichia coli 3-deoxy-D-manno-2-octulosonic acid 8-phosphate

Correspondence to: Ronald W. Woodard; e-mail: rww@umich.edu.
(KDO 8-P) synthase (P17579) and E. coli 3-deoxy-Darabino-2-heptulosonic acid 7-phosphate (DAH 7-P) synthase (Phe sensitive) (P00886). These enzymes comprise fully one-half of all those studied that catalyze the cleavage of the $\mathrm{C}-\mathrm{O}$ bond of PEP in the course of reaction. Unfortunately, the lack of a defined relationship between these enzymes lead researchers to believe that similarities between them were purely coincidental.

KDO 8-P synthase catalyses the first committed step in the production of $\mathrm{KDO}$, an integral part of the inner core region of the lipopolysaccharide layer (LPS) in Gram-negative (G-) bacteria. KDO acts as a linker between lipid $\mathrm{A}$ and the $\mathrm{O}$-antigen region (Levin and Racker 1959). Rick and Osborn (1972) first determined that disruption of KDO 8-P synthase leads to cessation of DNA, RNA, and protein synthesis and eventual cellular death. These and other studies were performed on a strain of Salmonella typhimurium which encoded a temperature-sensitive form of KDO 8-P synthase. Traditionally, both KDO 8-P synthase and the LPS were thought to be unique to $\mathrm{G}-$ bacteria. Recently however, $\mathrm{KDO}$ has been isolated from plant tissue and KDO 8-P synthase activity reported in crude tissue preparations (Sakurai et al. 1996). Homogeneous KDO 8-P synthase from a plant species has not been reported.

DAH 7-P synthase, ubiquitous in bacteria, fungi, and plants, is the first enzyme in the Shikimate pathway. This pathway is responsible for the generation of the intermediate compounds, chorismate and prephenate, which lead to the production of the aromatic amino acids (Phe, Tyr, Trp), catechols, and $p$-aminobenzoic acid (folic acid biosynthesis) (Walsh et al. 1996). Disruption of the Shikimate pathway can lead to rapid death of the organism. 
<smiles>C=C(O[Na])C(=O)O[Na]</smiles><smiles></smiles>

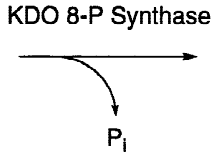

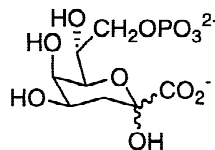<smiles>C=C(O[Na])C(=O)O[Na]</smiles><smiles></smiles>

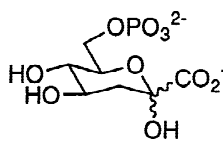

Fig. 1. Proposed chemical mechanisms of KDO 8-P synthase and DAH 7-P synthase.
This phenomenon is exploited by the commercially available herbicide, Roundup, which contains $N$ phosphonomethylglycine (glyphosate), a powerful inhibitor of enolpyruvyl shikimate 3-phosphate synthase (Steinrucken and Amrhein 1980), an enzyme downstream of DAH 7-P synthase in the Shikimate pathway. DAH 7-P synthase has not been targeted by antimicrobial research. Neither KDO 8-P synthase nor DAH 7-P synthase has a known counterpart in mammalian physiology (Raetz 1990), making both attractive targets for antimicrobial compounds.

Both KDO 8-P and DAH 7-P synthases catalyze a reaction between phosphoenolpyruvate (PEP) and a phosphorylated monosaccharide, arabinose 5-phosphate (A5P) in the case of the former (Levin and Racker 1959) and erythrose 4-phosphate (E4P) for the latter (Srinivasan and Sprinson 1959) (Fig. 1). The respective reactions appear to proceed by a common mechanism involving attack from the si face of PEP onto the re face of the monosaccharide aldehyde, following a proposed attack by water onto the C2 position of PEP (DeLeo et al. 1973; Dotson et al. 1993; Kohen et al. 1993; Onderka and Floss 1969a, b). There is, however, one prominent difference between $E$. coli KDO 8-P synthase and E. coli DAH 7-P synthase in the literature: DAH 7-P synthase requires a divalent metal for catalysis (Srinivasan and Sprinson 1959), while KDO 8-P synthase does not (Ray 1980). It has been shown through metal analysis (Stephens and Bauerle 1991) and chemical modification experiments (Stephens and Bauerle 1992) that the metal required for DAH 7-P synthase activity is likely catalytic rather than structural. Based on the paucity of sequence similarity between E. coli KDO 8-P synthase and E. coli DAH 7-P synthase ( $18 \%$ identity) and the difference in metal requirement, the mechanistic relationship between these two enzymes has been assumed to be primarily coincidental.

In the last year, however, two important events have occurred in the study of these enzyme groups. First, representative X-ray crystal structures of both enzymes have become available, the E. coli KDO 8-P synthase structure by the Gatti laboratory in collaboration with our own (Radaev et al. 2000) and the E. coli DAH 7-P synthase (Phe sensitive) structure by Kretsinger and co-workers (Shumilin et al. 1999). Second, recombinant KDO 8-P synthase from the hyperthermophile Aquifex aeolicus (AAC06457) has been overexpressed in E. coli and characterized (Duewel et al. 1999). The A. aeolicus KDO 8-P synthase, while having many of the same characteristics as the E. coli enzyme, requires a divalent metal for catalysis (Duewel and Woodard 2000). This poses an interesting series of questions.

(1) Is A. aeolicus KDO 8-P synthase indicative of a class of KDO 8-P synthases that requires a metal for catalysis or is a metallo-KDO 8-P synthase unique to this hyperthermophile?

(2) Is there, in parallel with a metallo-KDO 8-P synthase class, an unrecognized class of DAH 7-P synthases that does not require a metal?

(3) Does the existence of these hypothetical metalloKDO 8-P synthase and nonmetallo-DAH 7-P synthase classes imply an evolutionary link between KDO 8-P synthase and DAH 7-P synthase?

(4) Did the ancestral KDO 8-P synthase require a metal or was it metal independent?

In this report, we propose the existence of a new class of KDO 8-P synthase enzymes that requires the presence of a divalent metal for catalytic activity and propose a class of DAH 7-P synthases that does not. ${ }^{1}$ Furthermore, we theorize that the evolutionary link between KDO 8-P synthase and DAH 7-P synthase is one of divergence and that the ancestral KDO 8-P synthase was a metalloenzyme. The identification of new classes of KDO 8-P and DAH 7-P synthases allows for the opportunity to define further the similarities and differences between them.

\section{Methods}

Protein sequences showing similarity to that of E. coli KDO 8-P synthase were identified using the Basic Local Alignment Search Tool (BLAST), specifically tblastn (Altschul et al. 1990), primarily from the National Center for Biotechnology Information website (other sources of data are referenced in Table 1). All primary sequence alignments

\footnotetext{
${ }^{1}$ Class I (enzyme) refers to the putative nonmetallo-KDO 8-P and DAH 7-P synthases, while Class II (enzyme) refers to their putative metal-containing homologues.
} 
Table 1. Compilation of accession numbers and references for all sequences used in the analysis

\begin{tabular}{|c|c|c|c|c|c|}
\hline \multirow[b]{2}{*}{ Organism } & \multirow[b]{2}{*}{$\begin{array}{l}\text { Gram }+/-, \\
\text { archeae, } \\
\text { plant }\end{array}$} & \multicolumn{2}{|c|}{ Included in tree } & \multirow[b]{2}{*}{ Reference $^{\mathrm{a}}$} & \multirow[b]{2}{*}{$\begin{array}{l}\text { Accession no. } \\
\text { (KDO 8-P synthase/ } \\
\text { DAH 7-P synthase) }\end{array}$} \\
\hline & & $\begin{array}{l}\text { KDO 8-P } \\
\text { synthase } \\
\text { (Fig. 2) }\end{array}$ & $\begin{array}{l}\text { DAH 7-P } \\
\text { synthase } \\
\text { (Fig. 3) }\end{array}$ & & \\
\hline Actinobacillus actinomycetemcomitans & - & Yes & Yes & University of Oklahoma-NIDR ${ }^{\mathrm{c}}$ & n.a./n.a. \\
\hline Actinobacillus pleuropneumoniae & - & Yes & & Ward et al. (1998) & O68662/- \\
\hline Arabadopsis thaliana & Plant & Yes & Yes & TIGR & n.a./P29976. \\
\hline Aquifex aeolicus & - & Yes & & Deckert et al. (1998) & O66496/- \\
\hline Bacillus subtilis & + & & Yes & Kunst et al. (1997) & -/BG10286 \\
\hline Bordetella bronchiseptica & - & Yes & & Sanger-Beowolf Genomics & n.a./- \\
\hline Bordetella pertussis & - & Yes & Yes & Sanger-Beowolf Genomics & n.a./n.a. \\
\hline Campylobacter jejuni & - & Yes & & Sanger-Beowolf Genomics & n.a./- \\
\hline Caulobacter crescentus & - & Yes & & TIGR-DOE & n.a./- \\
\hline Chlamydia pneumoniae & - & Yes & Yes & Kalman et al. (1999) & Q9Z714/AAD18624 \\
\hline Chlamydia psittaci & - & Yes & & TIGR - NIAID & Q46225/- \\
\hline Chlamydia trachomatis & - & Yes & Yes & Stephens et al. (1988) & P77849/AAC67978 \\
\hline Chlorobium tepidum & - & Yes & Yes & TIGR-DOE & n.a./n.a. \\
\hline Clostridium acetobutyricum & + & & Yes & Genome Therapeutics-DOE & —/n.a. \\
\hline Corynebacterium glutamicum & + & & Yes & LION Bioscience—Degusa & —/n.a. \\
\hline Deinococcus radiodurans & + & & Yes & White et al. (1999) & —/n.a. \\
\hline Enterococcus faecalis & + & & Yes & TIGR—NIAID & —/n.a. \\
\hline Escherichia coli & - & Yes & Yes & Blattner et al. (1997) & P17579/P00886 \\
\hline Haemophilus influenzae & - & Yes & Yes & Fleischmann et al. (1995) & $\mathrm{P} 45251 / \mathrm{P} 44303$ \\
\hline Helicobacter pylori $\mathrm{J} 99$ & - & Yes & & Alm et al. (1999) & AAD05587/- \\
\hline Helicobacter pylori 26695 & - & Yes & & TIGR-TIGR & n.a./_- \\
\hline Klebsiella pneumoniae & - & Yes & & Washington University Consortium & n.a./- \\
\hline Mycobacterium avium & + & & Yes & TIGR-NIAID & —/n.a. \\
\hline Neisseria gonorrhoeae & - & Yes & & University of Oklahoma-NIAID & CAB44938/- \\
\hline Neisseria meningitidis & - & Yes & Yes & TIGR-TIGR & CAB44959/n.a. \\
\hline Pasteurella multocida & - & Yes & & $\begin{array}{l}\text { University of Minnesota } \\
\text { Computational Biology Center- } \\
\text { USDA-NRI/Minnesota Turkey } \\
\text { Growers Association }\end{array}$ & n.a./- \\
\hline Pasteurella haemolytica & - & Yes & & LION Bioscience & P95514/- \\
\hline Pisum sativum & Plant & Yes & & & n.a./- \\
\hline Porphyromonas gingivalis & - & Yes & & TIGR—NIDR & n.a./- \\
\hline Pseudomonas aeruginosa & - & Yes & Yes & $\begin{array}{l}\text { University of Washington-Cystic } \\
\text { Fibrosis Foundation }\end{array}$ & Q9ZFK4/n.a. \\
\hline Pyrococcus abyssi & Arch. & & Yes & Genoscope & —/n.a. \\
\hline Pyrococcus furiosus & Arch. & & Yes & Utah Genome Center & —/n.a. \\
\hline Rickettsia prowazekii & - & Yes & Yes & Andersson et al. (1998) & Q9ZE84/n.a. \\
\hline Salmonella typhi & - & Yes & Yes & Sanger-Wellcome Trust & n.a./n.a. \\
\hline Shewanella putrefaciens & - & Yes & & TIGR-DOE & n.a./- \\
\hline Solanum tuberosum & Plant & & Yes & Zhao and Herrmann (1992) & —/M95201 \\
\hline Staphylococcus aureus & + & & Yes & TIGR—NIAID/MGRI & —/n.a. \\
\hline Streptococcus pyogenes & + & & Yes & University of Oklahoma & —/n.a. \\
\hline Thermotoga maritima & - & & Yes & Nelson et al. (1999) & —/n.a. \\
\hline Vibrio cholerae & - & Yes & & TIGR—NIAID & n.a./- \\
\hline Yersinia pestis & - & Yes & Yes & Sanger-Beowolf Genomics & n.a./n.a. \\
\hline
\end{tabular}

${ }^{a}$ If unpublished data, the organization performing the sequencing is followed by the funding agency, where known.

${ }^{\mathrm{b}}$ n.a., not available; - , sequence not used.

${ }^{\mathrm{c}}$ DOE, U.S. Department of Energy; JGI-DOE; Joint Genome Institute-U.S. Department of Energy; MGRI, Merck Genome Research In-

were accomplished using ClustalW (Thompson et al. 1994) on a Silicon Graphics O2 computer. The BLOSUM (Henikoff and Henikoff 1992) series was used for the protein weight matrix. Phylogenetic analyses were completed using PHYLIP (Phylogeny Inference Package, v3.5c) and PAML (Phylogenetic Analysis by Maximum Likelihood, v3.0a).

Sequences of the two proteins (KDO 8-P synthase and DAH 7-P synthase) were aligned using ClustalW. Phylogenetic relationships were calculated by maximum-likelihood analysis using AAML stitute; NIAID, National Institute of Allergy and Infectious Diseases; NIDR, National Institute of Dental \& Craniofacial Research; Sanger, The Sanger Centre; TIGR, The Institute for Genomic Research; USDA-NRI, U.S. Department of Agriculture-National Research Initiative.

(codeml: seqtype $=2$ ) in the PAML package. To decrease the calculation time, an initial tree search was performed using a parsimony approach. The sequence alignment was bootstrapped using SeqBoot followed by parsimony analysis using ProtPars (100 replicates). The 100 most parsimonious trees were then used as input in the AAML program for maximum-likelihood analysis. The evolutionary model described by Jones (1992) with actual amino acid frequencies was used and the $\gamma$ distribution was estimated $(\mathrm{JTT}+\mathrm{F}+\gamma)$. The differences in 
Table 2. Statistical data from the maximum-likelihood analysis of 30 KDO 8-P synthases

\begin{tabular}{lllll}
\hline Tree no. & $\begin{array}{l}- \text {-ln likelihood } \\
(\mathrm{JTT}+\mathrm{F}+\gamma)\end{array}$ & SE & $\begin{array}{l}\text { Bootstrap } \\
\text { proportion }\end{array}$ & $\begin{array}{l}\text { Gamma shape } \\
\text { factor }(\alpha)\end{array}$ \\
\hline 10 & -8567.590 & - & 0.340 & 0.82549 \\
12 & -8570.747 & 11.335 & 0.157 & 0.82871 \\
\hline
\end{tabular}

maximum-likelihood values were evaluated using the method of Kishino and Hasegawa (1989) implemented in AAML. Figures were prepared in part using Drawtree and Drawgram in the PHYLIP package. Unless otherwise stated, all parameters in both ProtPars and AAML were the default values. A molecular clock was not assumed due to the lack of reliable rooting information.

Putative Class II KDO 8-P synthases (Helicobacter pylori J99, Chlamydia psittaci) were overexpressed and purified as described by Duewel et al. (1999) with the exception of the heat precipitation step. KDO 8-P synthases were treated with $10 \mathrm{~m} M$ ethylenediaminetetraacetic acid (EDTA), $10 \mathrm{~m} M$ dipicolinic acid, or $10 \mathrm{~m} M 1$,10phenanthroline to sequester metal away from the enzyme. Typically, excess chelator was removed via Amicon diaflow filtration and enzymatic assays were performed as described previously (Schoner and Herrmann 1976) in both the absence and the presence of $1 \mathrm{~m} M$ divalent metal ( $\mathrm{Mg}, \mathrm{Zn}, \mathrm{Mn}$, or Fe). An enzyme is classified as metal dependent if chelator renders it inactive ( $<5 \%$ remaining activity) and the subsequent addition of metal to the apoenzyme restores it to full activity. Conversely, a homologue is determined to be metal independent if neither chelator nor exogenous metal results in a greater than $10 \%$ change in activity

\section{Results}

\section{Phylogenetic Analysis of KDO 8-P Synthase}

Based on BLAST searches conducted using the genomic database, primarily at the NCBI (for others see Table 1), 29 complete and publicly available sequences were identified that demonstrate $>40 \%$ identity with the wellstudied E. coli KDO 8-P synthase. Two of these sequences (Arabadopsis thaliana and Pisum sativum) are from plant species. Although there are no literature reports of homogeneous KDO 8-P synthase isolated from plant tissue, both of these sequences were included in the interest of completeness.

From the maximum-likelihood analysis of 100 possible trees tested, only two have a bootstrap proportion greater than 0.1 (Table 2). Only the most likely tree (tree 10) is shown in Fig. 2. Both of these two phylogenetic trees divide the enzyme sequences into identical classes, with only minor reorganization within the two classes. From Fig. 2, it is readily apparent that two large groups of KDO 8-P synthase (Class I and Class II) exist.

\section{Analysis of KDO 8-P Synthases from H. pylori $J 99$ and C. psittaci}

Recombinant $H$. pylori $\mathrm{J} 99$ and the $C$. psittaci KDO 8-P synthases were expressed and isolated from E. coli and assayed for metal dependence. Upon treatment with EDTA, dipicolinic acid, and/or 1,10-phenanthroline, both enzymes are substantially inactivated (Table 3), while the inclusion of divalent metal in the assay mixture dramatically raises the activity of each enzyme.

\section{Phylogenetic Analysis of DAH 7-P Synthase}

Twenty-five DAH 7-P synthases were chosen in a manner similar to that described for KDO 8-P synthase. Unlike KDO 8-P synthase, however, DAH 7-P synthase exists in Bacteria, Archea, and Eucarya. Representatives from all of these domains were included in the DAH 7-P synthase analysis. Similarly to the phylogenetic tree generated for KDO 8-P synthase, the DAH 7-P synthases separate into two distinct classes. In the case of DAH 7-P synthase, however, maximum-likelihood analysis generated only a single significant tree. This tree is shown in Fig. 3.

\section{Discussion}

It is apparent from the KDO 8-P synthase phylogenetic tree (Fig. 2) that two classes of enzyme exist. We propose that the unifying trait of Class I is the lack of a metal requirement, while that of Class II is the requirement of a divalent metal for catalysis. The KDO 8-P synthases from E. coli (Ray 1980), Salmonella typhimurium (Taylor et al. 2000), Neisseria gonorrhoeae (Sheflyan et al. 2000), A. aeolicus (Duewel and Woodard 2000), H. pylori J99, and $C$. psittaci have all been characterized. The enzymes from E. coli, S. typhimurium, and $N$. gonorrhoeae have all been shown to catalyze the condensation reaction in the absence of any metal cofactor. It has been reported that KDO 8-P synthase from A. aeolicus requires a divalent metal for activity. Here we report that, based on a preliminary characterization, the enzymes from $H$. pylori $\mathrm{J} 99$ and $C$. psittaci also require a divalent metal for catalytic activity. As shown in Fig. 2, the three known nonmetallo-KDO 8-P synthases (E. coli, S. typhimurium, and N. gonorrhoeae) are all members of Class I in the phylogenetic tree. Conversely, the metallo-KDO 8-P synthases from A. aeolicus, H. pylori J99, and C. psittaci all belong to Class II. Beyond the obvious difference of metal requirement, the two classes of KDO 8-P synthase appear to be very similar in most other respects. Those enzymes fully characterized (E. coli, A. aeolicus, S. typhimurium, and N. gonorrhoeae) all share very similar biochemical properties, the only significant difference being the optimal temperature of the A. aeolicus KDO 8-P synthase. This is hardly surprising, as $A$. aeolicus is a hyperthermophilic organism, whereas the others are mesophiles. As the other proposed Class II KDO 8-P synthases are mesophiles, temperature optimum can be reasonably disregarded as the Class II uni- 


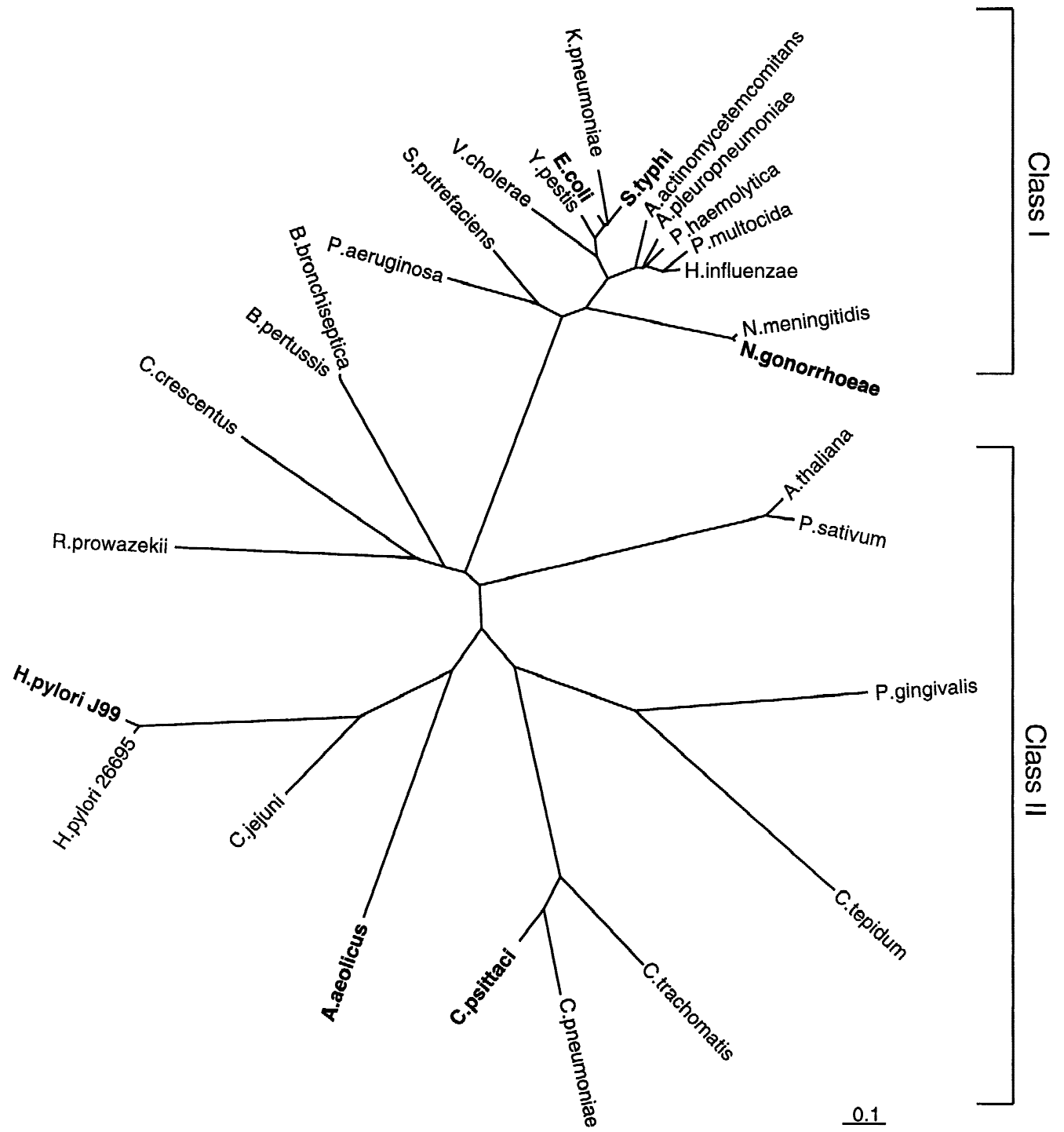

Fig. 2. Phylogenetic tree generated by maximum-likelihood analysis from the sequences of $29 \mathrm{KDO}$ 8-P synthase sequences from various organisms. The first group (Class I) is predicted to maintain the characteristics of the model E. coli enzyme (i.e., no metal requirement),

while the second group (Class II), including the A. aeolicus enzyme, is predicted to require a divalent metal for catalysis. Enzymes for which in vitro metal binding data are known are shown in boldface type.

Table 3. In vitro activity of KDO 8-P synthase

\begin{tabular}{llll}
\hline $\begin{array}{l}\text { Source of } \\
\text { recombinant }\end{array}$ & $\begin{array}{l}\text { Activity as } \\
\text { KDO 8-P } \\
\text { synthase }\end{array}$ & $\begin{array}{l}\text { Activity in the } \\
\text { presence of } \\
\left(k_{\text {cat }} ; \mathrm{min}^{-1}\right)\end{array}$ & $\begin{array}{l}\text { Activity in the } \\
\text { presence of }\end{array}$ \\
$\mathrm{EDTA}\left(\mathrm{min}^{-1}\right)$ & $\begin{array}{l}1 \mathrm{mM} \\
\mathrm{MnCl}_{2}\left(\mathrm{~min}^{-1}\right)\end{array}$ \\
$\begin{array}{l}\text { H. pylori } \mathrm{J} 99 \\
\text { C. psittaci }\end{array}$ & 20. & 0.82 & 58 \\
\hline
\end{tabular}

fying trait. That these in vitro data correlate well with the in silico phylogenetic data strongly supports the evolutionary division of Class I and Class II KDO 8-P synthases suggested in this report.

Having identified two classes of KDO 8-P synthase, we also propose a class of DAH 7-P synthase whose activity is not dependent on a metal cofactor. Figure 3
Table 4. Statistical data from the maximum-likelihood analysis of 30 DAH 7-P synthases

\begin{tabular}{lllll}
\hline Tree no. & $\begin{array}{l}- \text {-ln likelihood } \\
(\mathrm{JTT}+\mathrm{F}+\gamma)\end{array}$ & SE & $\begin{array}{l}\text { Bootstrap } \\
\text { proportion }\end{array}$ & $\begin{array}{l}\text { Gamma shape } \\
\text { factor }(\alpha)\end{array}$ \\
\hline 73 & $-16,405.84$ & - & 0.525 & 0.27197 \\
\hline
\end{tabular}

illustrates the phylogenetic tree generated for $28 \mathrm{DAH}$ 7-P synthase sequences. Again, the bifurcation of the tree into two distinct groups is readily evident. It is tempting to assign the E. coli DAH 7-P synthase, which is known to require a divalent metal for activity, to Class II and to assume that the other group is Class I DAH 7-P synthases. Support for this hypothesis can be found in the literature. Specifically, the DAH 7-P synthase from $\mathrm{Ba}$ cillus subtilis Marburg 168 has been initially character- 


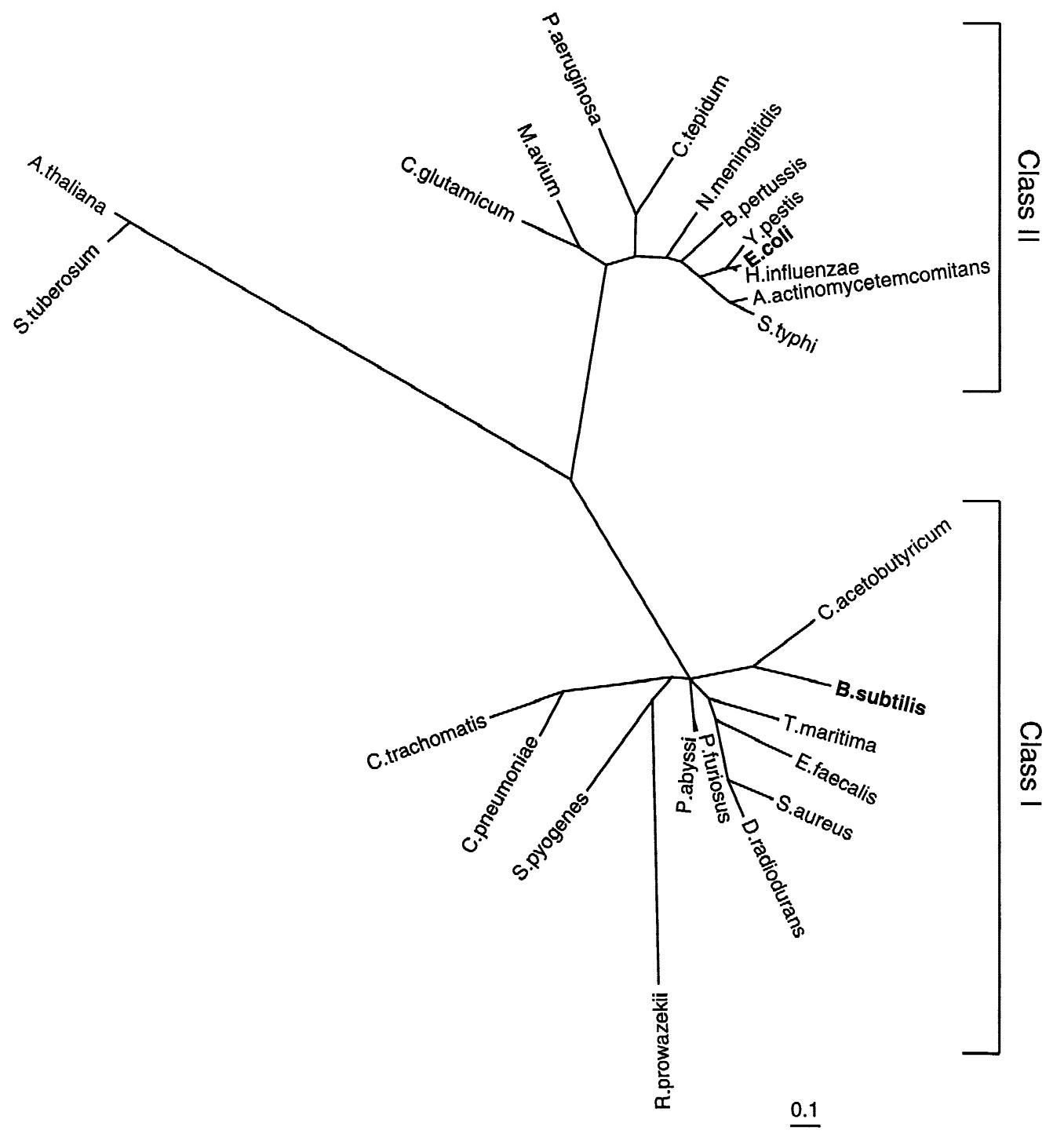

Fig. 3. Phylogenetic tree generated by maximum-likelihood analysis from 25 DAH 7-P synthase sequences. The group labeled Class I (including the $B$. subtilis enzyme) is postulated not to require a metal, while Class II enzymes (including the E. coli enzyme) are predicted to have a metal requirement. Enzymes for which in vitro metal binding data are known are shown in boldface type.

ized as a nonmetallo-DAH 7-P synthase. (Llewellyn et al. 1980) There exist several confounding factors, however, that make the assignment of the DAH 7-P synthase classes as metallo and nonmetallo less conclusive than in the case of KDO 8-P synthase. First, the B. subtilis protein, unlike that from E. coli, exhibits both DAH 7-P synthase and chorismate mutase activities. Second, while the feedback inhibitor of the E. coli DAH 7-P synthases is the ultimate pathway product (Phe, Tyr, or Trp), the $B$. subtilis enzyme is sensitive to an intermediate (prephenate) in the Shikimate pathway (Llewellyn et al. 1980). Therefore, it is possible that the difference between Class I and Class II DAH 7-P synthases is not metal requirement but, rather, allosteric effector.

The grouping of highly diverse species in the DAH 7-P synthase phylogeny is perhaps surprising. While these results appear to be statistically valid, it is unexpected that Archael species would be monophyletic with both $\mathrm{G}-$ and $\mathrm{G}+$ Bacteria and Eucarya. Also, it appears that there is a stronger than expected relationship between $\mathrm{G}+$ eubacteria and proteobacteria on the Class I portion of the tree; Class II contains only $\mathrm{G}-$ eubacteria. More expected, though, is the large distance between the plant and the bacterial DAH 7-P synthases. This was, of course, not the case in the KDO 8-P synthase phylogeny. Although these relationships may point to interesting phenomena such as lateral gene transfer, that these groupings are related to a different common trait among the Class I enzymes, other than metal independence, seems just as likely. Work currently progressing in our laboratory is aimed toward clarifying the relationship among the DAH 7-P synthases.

While it has been suggested that KDO 8-P synthase and DAH 7-P synthase are mechanistically related, the existence of Class II KDO 8-P synthases and Class I DAH 7-P synthases suggests a much closer evolutionary 
link between the two enzymes than has been previously thought. ${ }^{2}$ Unfortunately, the extremely low sequence similarity between the 29 KDO 8-P synthases and the 25 DAH 7-P synthases ( $<5 \%$ identity) limits the value of statistical techniques in establishing the relationship between them. Therefore, we have chosen a necessarily qualitative assessment of their connection. Although the lack of primary sequence similarity between the KDO 8-P synthases and the DAH 7-P synthases may at first glance seem to indicate the convergent evolution of these two important enzymes, other observations potentially indicate divergent evolution. In an attempt to relate enzyme families, a set of six criteria for judging the likelihood of divergent rather than convergent evolution has been put forth (Matthews et al. 1981). These criteria include the similarity of DNA sequence, protein sequence, three-dimensional structure, enzyme-substrate interaction, and catalytic mechanism and that the segments essential for catalysis occur in the same sequence (i.e., not transposed). This is, of course, not as rigorous an assessment of the relationship between two enzyme families as statistical techniques would be. KDO 8-P synthase and DAH 7-P synthase appear to fall within the bounds of divergence as described by these criteria.

First, while neither the DNA nor the protein sequences of E. coli KDO 8-P and DAH 7-P synthase necessarily suggest a strong relationship, even a cursory examination of the X-ray crystal structures reveals startling similarities. Both E. coli $\mathrm{KDO}$ 8-P synthase and DAH 7-P synthase fold into a $(\beta / \alpha)_{8}$ tertiary structure (TIM barrel); their structures are superimposable with a $\mathrm{C}_{\alpha}$ RMS deviation of $1.83 \AA$ (Radaev et al. 2000). Crystallographic data on A. aeolicus KDO 8-P synthase shows that it folds into a TIM barrel whose backbone is virtually indistinguishable from that of the $E$. coli enzyme. The high level of tertiary structure similarity between KDO 8-P synthase and DAH 7-P synthase suggests divergence from a common ancestor.

Second, many of the active-site residues are the same in KDO 8-P synthase and DAH 7-P synthase. The residues responsible for metal binding in E. coli DAH 7-P synthase (Phe sensitive) are Cys, His, Glu, and Asp (Shumilin et al. 1999). Similarly, a Cys, a His, a Glu, and an Asp in A. aeolicus KDO 8-P synthase appear to be involved in metal binding. These residues correspond to $E$. coli $\mathrm{KDO}$ 8-P synthase N26, H202, E239, and D250 (all numbering refers to the E. coli $\mathrm{KDO}$ 8-P synthase); the

\footnotetext{
${ }^{2}$ Jensen and colleagues noted the existence of two classes of DAH 7-P synthase (Subramaniam et al. 1998) but failed to place KDO 8-P synthase into the proper context with respect to DAH 7-P synthase. This resulted in grouping all KDO 8-P synthases with Class I DAH 7-P synthase. The division was attributed to a difference between "narrowsubstrate specificity" and "broad-substrate specificity" KDO 8-P synthases; this division has been shown to be erroneous (Sheflyan et al. 2000).
}

latter three amino acids are highly conserved in all KDO 8-P synthases. Residue 26, which aligns with the abovementioned Cys in A. aeolicus KDO 8-P synthase and $E$. coli DAH 7-P synthase, is Asn in E. coli KDO 8-P synthase and all proposed Class I KDO 8-P synthases. As in A. aeolicus KDO 8-P synthase, this position is occupied by a Cys in all Class II KDO 8-P synthases and DAH 7-P synthases. This again speaks to the similarity of structure, especially of active-site structure, between the KDO 8-P synthases and the DAH 7-P synthases as well as to the point that essential residues occur in the same order across all classes of both enzymes.

The binding sites for both PEP and A5P or E4P (Figs. 4a and b, respectively) are also similar in E. coli KDO 8-P synthase and DAH 7-P synthase. In the case of PEP, the phosphate moiety is bound in E. coli KDO 8-P synthase by A116, K138, and R168 (Radaev et al. 2000) and by homologous residues in DAH 7-P synthase (Shumilin et al. 1999). The carboxylate moiety is bound by K55/ K60/K138 in E. coli KDO 8-P synthase and Arg, Lys, and Lys in DAH 7-P synthase. Of the six residues involved in binding PEP in both enzymes, five are identical, with the sixth representing a conservative substitution $(\mathrm{K} \rightarrow \mathrm{R})$. In addition, all six residues occur in the same order and with very similar spacing $[\mathrm{A}-\mathrm{x}(22)-\mathrm{K}-$ $\mathrm{x}(30,48)-\mathrm{K}$ (standard PROSITE nomenclature) (see Bucher and Bairoch 1994) for the phosphate binding site and $[K R]-x(5)-K-x(78,89)-K$ for the carboxylate binding site]. In binding the monosaccharide phosphate, an active-site loop is involved in both KDO 8-P synthase and DAH 7-P synthase. This small loop is responsible for positioning the monosaccharide phosphate, and hence the entire monosaccharide, so as to allow for the proper distance between PEP and the monosaccharide carbonyl for efficient reaction. In the E. coli enzymes, the sequence ${ }^{60} \mathrm{KANRS}$ is predicted to bind to the terminal phosphate of the five-carbon monosaccharide in KDO 8-P synthase, while the sequence ${ }^{97} \mathrm{KP}-\mathrm{RT}$ is responsible for the same function with the four-carbon analogue in DAH 7-P synthase. The substitution of Pro in DAH 7-P synthase for Ala and Asn in KDO 8-P synthase allows this slightly shortened loop to turn more sharply in DAH 7-P synthase than in KDO 8-P synthase, bringing the remaining sequence approximately $1.8 \AA$ closer to the center of the active site and PEP. This shift in the DAH 7-P synthase active site then allows for the correct positioning of the slightly shorter E4P. The only other difference (Ser to Thr) is a very conservative substitution. Similarity of the binding sites for both substrates is indicative both of similarity of enzyme-substrate interaction and of nontransposed active site residues.

Finally, as mentioned in the Introduction, the proposed mechanisms of KDO 8-P synthase and DAH 7-P synthase are largely the same. In both cases, an activated water molecule is believed to attack at C2 of PEP followed by (or concurrent with) an attack of C3 of PEP on 

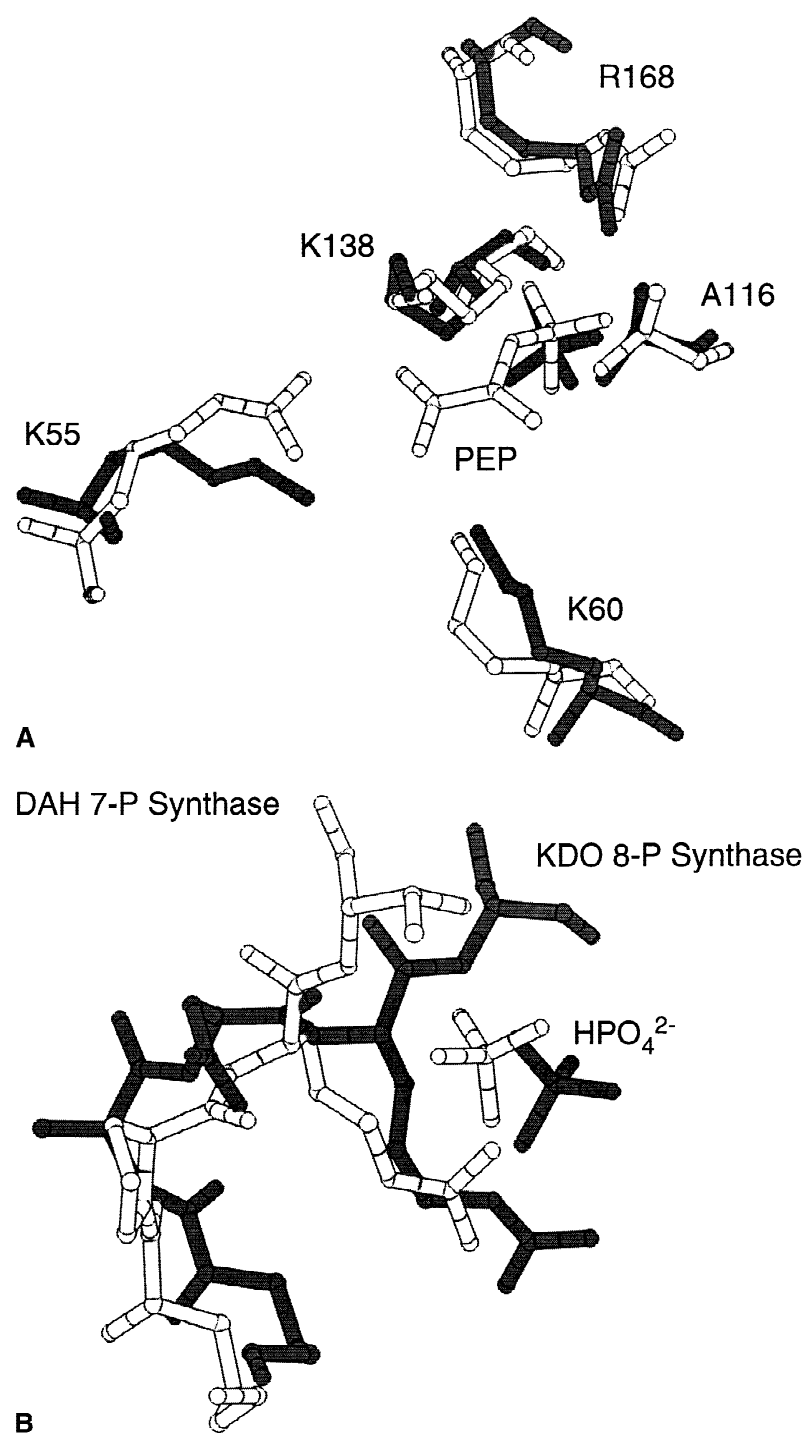

Fig. 4. A Superposition of the PEP binding sites of E. coli KDO 8-P synthase (shaded residues) and DAH 7-P synthase (white residues). PEP is present in the DAH 7-P synthase structure, while only a sulfate is present in the KDO 8-P synthase structure; both are labeled PEP. Residue numbering is that of $E$. coli KDO 8-P synthase. B Superposition of the monosaccharide phosphate binding sites of $E$. coli KDO 8-P synthase (shaded residues) and DAH 7-P synthase (white residues). The two phosphate groups shown represent the terminal phosphate of A5P or E4P, respectively, and are approximately $1.8 \AA$ apart.

$\mathrm{C} 1$ of A5P or E4P. In both KDO 8-P synthase and DAH 7-P synthase, the phosphate is cleaved at the $\mathrm{C}-\mathrm{O}$ bond, rather than the more typical $\mathrm{P}-\mathrm{O}$ bond (DeLeo and Sprinson 1968; Dotson et al. 1995; Hedstrom and Abeles 1988), and the reaction stereochemistry (Dotson et al. 1993; Kohen et al. 1993; Onderka and Floss 1969b) is identical in both enzyme systems.

In the case of these two enzyme families, four of the six criteria for divergent evolution are met: they have similar three-dimensional structures, similar enzymesubstrate interactions (both substrates and metal), proposed active-site residues occurring in the same order (metal and substrate binding sites), and similar (pro- posed) catalytic mechanisms. Taken together, the above data provide a high level of evidence that these two enzymes share some distant common ancestor. ${ }^{3}$

It is also apparent from the maximum-likelihood analysis that the Class I KDO 8-P synthases are more closely related to one another than the Class II enzymes. The Class I KDO 8-P synthases would then represent a relatively recent offshoot of an ancestral Class II KDO 8-P synthase and, having had less time to evolve, do not show the same degree of divergence. This is well demonstrated in Fig. 2, wherein the Class II KDO 8-P synthases have consistently longer branch lengths than their Class I counterparts.

Given knowledge of the phylogenetic relationship between Class I and Class II KDO 8-P synthases, features of the primary sequence alignment (Fig. 5) become easier to interpret. Perhaps the most interesting regions of the alignment are those that both demonstrate a high level of conservation unique to each class of KDO 8-P synthase and show marked differences between the two classes (intraclass versus interclass similarity). For example, C38 (E. coli KDO 8-P synthase numbering) is known to be essential for activity of the E. coli homologue (Salleh et al. 1996). In all other Class I KDO 8-P synthases, a Cys occupies the analogous position. In the Class II homologues, however, an Ala (or Gly in one case) aligns with this position. Similarly, the metal binding site includes one Cys residue, which corresponds to C11 (E. coli residue 26) in the A. aeolicus sequence. Again, this residue is completely conserved in all Class II KDO 8-P synthases but is uniformly absent in their Class I brethren; an Asn exists in its place. Due to the small number of these sites, it seems reasonable that most, if not all, are involved either with the metal's catalytic role in the Class II KDO 8-P synthases or with compensating for the lack of metal in the Class I KDO 8-P synthases. It is worth noting that while there are several residues or pairs of residues that meet this criterion, no multiple residue string falls into this category. Thus little or no structural alteration was needed to affect the change from Class II to Class I; only specific amino acid functional groups were transformed. Consequently, overall interclass similarities remain significant, while those residues most likely involved in the evolution from the ancestral Class II to the modern Class I KDO 8-P synthases are highlighted.

The existence of two classes of both KDO 8-P synthase and DAH 7-P synthase has not been considered previously. The difference in metal requirement and lack of obvious sequence similarity between $E$. coli KDO 8-P synthase and DAH 7-P synthase were often thought to outweigh the mechanistic similarities of the reactions

\footnotetext{
${ }^{3}$ Indeed, it has even been proposed that all $(\beta / \alpha)_{8}$ enzymes may have diverged from a very distant common ancestor (Farber and Petsko, 1990).
} 


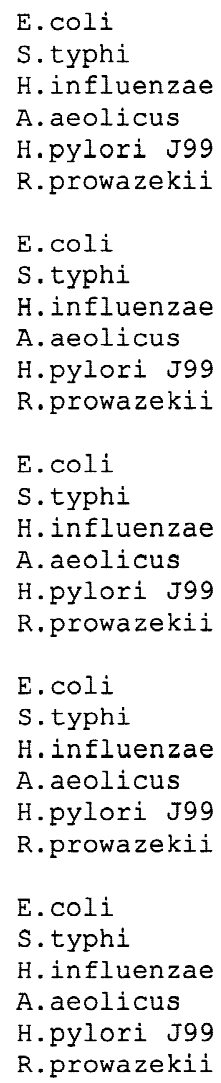

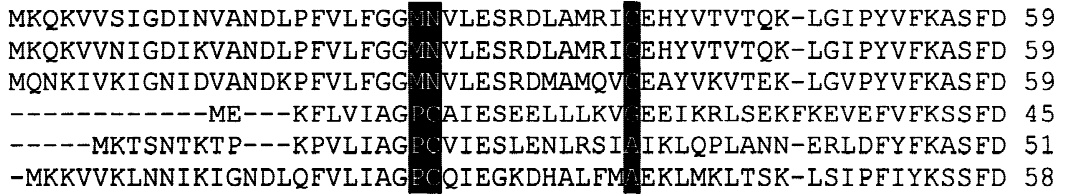

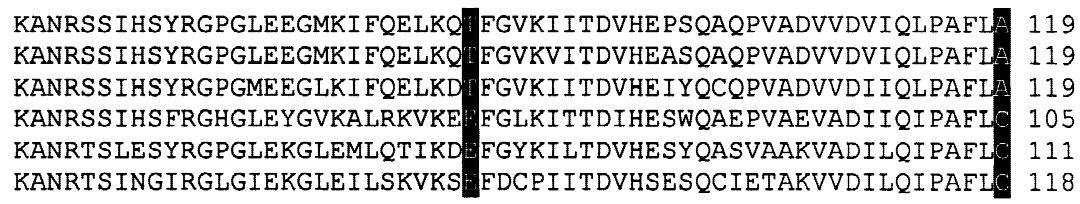

RQTDLVEAMAKTGAVINVKKPQFVSPGQMGN-IVDKFKEGG---1----NEKVILC 166 RQTDLVEAMAKTGAVINVKKPQFVSPGQMGN-IVDKFHEGG-----------NDKVILC 166 RQTDLVEAMAKTGAVINVKKPQELSPSQMGN-IVEKIEECG---------NDKI I LC 166 RQTDLLLAAAKTGRAVNVKKGQFLAPWDTKN-VVEKLKFG--G----------AKEIYLT 152 RQTDLIVEVSQTNAIVNI KKGQFMN PKDMQYSVLKALKTRDSSIQSPTYETALKNGVWLC 171 RQTDLLKAAAKTGKIVKVKKGQFLAPWDMKN-VQKKLEVFG------_-_AKDILFT 165

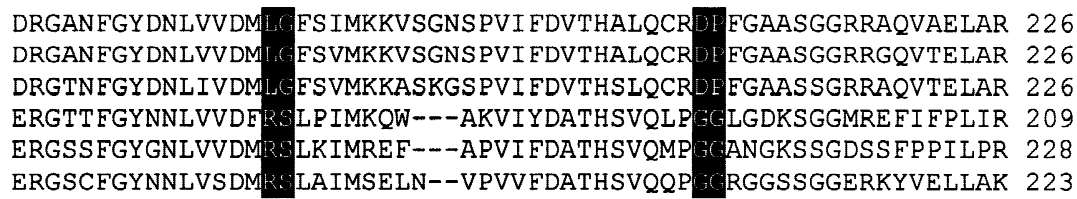

AGMAVGLAGLFIEAHPDPEHAKCDGPSALPLAKLE PFLKQMKAIDDLVKGFEELDTSK 284 AGMAVGLAGLFLESHPDPANAKCDGPSALPLAKLEQFLTQIKAIDDLVKSFDELDTEN 284 SGLAVGIAGLFLEAHPNPNQAKCDGPSALPLSALEGFVSQMKAIDDLVKSEPELDTSI 284 AAVAVGCDGVFMETHPEPEKALSDASTQLPLSQLEGI IEAILEIREVASKYYETI PVK 267 AAAAVGIDGLFAETHIDPKNALSDGANMLKPDELEHLVTDMLKIQNLF-------- 276 AAISVGIAGIYMEVHQDPDNAPSDGPCMIKLDNLESILIKLKKYDKITKEIV-_--- 275

Fig. 5. A representative alignment of three Class I and three Class II KDO 8-P synthases. Residues that are identical intraclass and show a marked difference interclass are indicated by shading.

catalyzed by these two enzymes. Now, with the characterization of the KDO 8-P synthase from A. aeolicus, $H$. pylori $\mathrm{J} 99$, and C. psittaci and the structural information available for both E. coli enzymes and the KDO 8-P synthase from A. aeolicus, the existence of Class II KDO 8-P synthases and Class I DAH 7-P synthases seems not only plausible but likely. Furthermore, these data support a scenario wherein KDO 8-P synthase and DAH 7-P synthase have more in common than once thought; the data suggest that KDO 8-P synthase and DAH 7-P synthase may actually share a common ancestor. To provide experimental evidence of these predictions, we have cloned the KDO 8-P synthase gene from several diverse species of bacteria and are in the process of purifying and characterizing the recombinant proteins for metal requirement. We are in the preliminary stages of crystallizing the $B$. subtilis protein as well as overexpressing several DAH 7-P synthases to further the comparison of Class I DAH 7-P synthases with their Class II counterparts. By establishing both a second class of KDO 8-P synthase and a divergent relationship between KDO 8-P and DAH 7-P synthases, we can begin to shed light on the relationship between these unique enzymes and further the knowledge of both groups.

Acknowledgments. This work was supported by NIH Research Grants GM 53069 (R.W.W.) and T32 GM07767 (M.R.B.).

\section{References}

Alm RA, Ling LL, Moir DT, et al. (1999) Genomic-sequence comparison of two unrelated isolates of the human gastric pathogen Helicobacter pylori. Nature 397:176-180

Altschul SF, Gish W, Miller W, Myers EW, Lipman DJ (1990) Basic local alignment search tool. J Mol Biol 215:403-410

Andersson SGE, Zomorodipour A, Andersson JO, et al. (1998) The genome sequence of Rickettsia prowazekii and the origin of mitochondria. Nature 396:133-140

Blattner FR, Plunkett III G, Bloch CA, et al. (1997) The complete genome sequence of Escherichia coli K-12. Science 277:1453-1474

Bucher P, Bairoch A (1994) A generalized profile syntax for biomolecular sequence motifs and its function in automatic sequence interpretation. In: Altman R, Brutlaf D, Karp P, Lathrop R, Searls D (eds) ISMB-94; Proceedings 2nd International Conference on Intelligent Systems for Molecular Biology. AAAI Press, Menlo Park, CA, pp 53-61

Deckert G, Warren PV, Gaasterland T, et al. (1998) The complete genome of the hyperthermophilic bacterium Aquifex aeolicus. Nature 392:353-358

DeLeo AB, Sprinson DB (1968) Mechanism of 3-deoxy-D-arabinoheptulosonate 7-phosphate (DAHP) synthetase. Biochem Biophys Res Commun 32:873-877

DeLeo AB, Dayan J, Sprinson DB (1973) Purification and kinetics of tyrosine-sensitive 3-deoxy-D-arabino-heptulosonic acid 7-phosphate synthetase from Salmonella. J Biol Chem 248:2344-2353

Dotson GD, Nanjappan P, Reily M, Woodard RW (1993) Stereochemistry of 3-deoxyoctulosonate 8-phosphate synthase. Biochemistry 32:12392-12397

Dotson GD, Dua RK, Clemens JC, Wooten EW, Woodard RW (1995) 
Overproduction and one-step purification of Escherichia coli 3-deoxy-D-manno-octulosonic acid 8-phosphate synthase and oxygen transfer studies during catalysis using isotopic-shifted heteronuclear NMR. J Biol Chem 270:13698-13705

Duewel HS, Woodard RW (2000) A metal bridge between two enzyme families: 3-Deoxy-D-manno-octulosonate 8-phosphate synthase from Aquifex aeolicus requires a divalent metal for activity. J Biol Chem 275:22824-22831

Duewel HS, Sheflyan GY, Woodard RW (1999) Functional and biochemical characterization of a recombinant 3-deoxy-D-mannooctulosonic acid 8-phosphate synthase from the hyperthermophilic bacterium Aquifex aeolicus. Biochem Biophys Res Commun 263: 346-351

Farber GK, Petsko GA (1990) The evolution of $\alpha / \beta$ barrel enzymes. Trends Biochem Sci 15:229-231

Fleischmann RD, Adams MD, White O, et al. (1995) Whole-gemone random sequencing and assembly of Haimophilus influenzae RD. Science 269:496-512

Hedstrom L, Abeles R (1988) 3-Deoxy-D-manno-octulosonate-8phosphate synthase catalyzes the C-O bond cleavage of phosphoenolpyruvate. Biochem Biophys Res Commun 157:816-820

Henikoff S, Henikoff JG (1992) Amino acid substitution matrices from protein blocks [BLOSSUM]. Proc Natl Acad Sci USA 89:109815110919

Jones DT, Taylor WR, Thornton JM (1992) The rapid generation of mutation data matrices from protein sequeces. Comput Appl Biosci 8:275-282

Kalman S, Mitchell W, Marathe R, et al. (1999) Comparative genomes of Chlamydia pneumoniae and C. trachomatis. Nature Genet 21: 385-389

Kishino H, Hasegawa M (1989) Evaluation of the maximum likelihood estimate of the evolutionary tree topologies from sequence data and branching order in Hominoidea. J Mol Evol 229:170-179

Kohen A, Berkovich R, Belakhov V, Baasov T (1993) Stereochemistry of the KDO8P synthase. An efficient synthesis of the 3-fluoro analogues of KDO8P. Bioorg Med Chem Lett 3:1577-1582

Kunst F, Ogasawara N, Moszer I, et al. (1997) The complete genome sequence of the Gram-positive bacterium Bacillus subtilis. Nature 390:249-256

Levin DH, Racker E (1959) Condensation of arabinose 5-phosphate and phosphorylenolpyruvate by 2-keto-3-deoxy-8-phosphooctonic acid synthetase. J Biol Chem 234:2532

Llewellyn DJ, Daday A, Smith GD (1980) Evidence for an artificially evolved bifunctional 3-deoxy-D-arabino-heptulosonate-7phosphate synthase-chorismate mutase in Bacillus subtilis. J Biol Chem 255:2077-2084

Matthews BW, Remington SJ, Grutter MG, Anderson WF (1981) Relation between hen egg-white lysozyme and bacteriophage-T4 lysozyme-Evolutionary implications. J Mol Biol 147:545

Nelson KE, Clayton RA, Gill SR, et al. (1999) Evidence for lateral gene transfer between Archaea and Bacteria from genome sequence of Thermotoga maritima. Nature 399:323-329

Onderka DK, Floss HG (1969a) Stereospecificity of the 3-deoxy-Darabino-heptulosonate 7-phosphate synthetase reaction. Biochem Biophys Res Commun 35:801-804

Onderka DK, Floss HG (1969b) Steric course of the chorismate synthetase reaction and the 3-deoxy-D-arabino-heptulononate 7-phosphate (DAHP) synthetase reaction. J Am Chem Soc 91:5894-5896

Radaev S, Dastidar P, Patel M, Woodard RW, Gatti DL (2000) Structure and mechanism of 3-deoxy-D-manno-oculosonate 8-phosphate synthase. J Biol Chem 275:9476-9484

Raetz CR (1990) Biochemistry of endotoxins. Annu Rev Biochem 59:129-170

Ray PH (1980) Purification and characterization of 3-deoxy-D-mannooctulosonate 8-phosphate synthetase from Escherichia coli. J Bacteriol 141:635-644
Rick PD, Osborn MJ (1972) Isolation of a mutant of Salmonella typhimurium dependent on D-arabinose-5-phosphate for growth and synthesis of 3-deoxy-D-manno-octulosonate-8-phosphate (ketodeoxyoctonate). Proc Natl Acad Sci USA 69:3756-3760

Sakurai MH, Matsumoto T, Kiyohara H, Yamada H (1996) Detection and tissue distribution of anti-ulcer pectic polysaccharides from Bupleurun falcatum by polyclonal antibody. Planta Med 62:341346

Salleh HM, Patel MA, Woodard RW (1996) Essential cysteines in 3-deoxy-D-manno-octulosonic acid 8-phosphate synthase from Escherichia coli: Analysis by chemical modification and sitedirected mutagenesis. Biochemistry 35:8942-8947

Schoner R, Herrmann KM (1976) 3-Deoxy-D-arabino-heptulosonate 7-phosphate synthase-Purification, properties, and kinetics of tyrosine-sensitive isozyme from Escherichia coli. J Biol Chem 251: 5440-5447

Sheflyan GY, Sundaram AK, Taylor WP, Woodard RW (2000) Substrate ambiquity of 3-deoxy-D-manno-octulosonate 8-phosphate synthase from Neisseria gonorrhoeae revisited. J Bacteriol 182: 5005-5008

Shumilin IA, Kretsinger RH, Bauerle R (1999) Crystal structure of phenylalanine-regulated 3-deoxy-D-arabino-heptulosonate-7phosphate synthase from Escherichia coli. Struct Fold Design 7: 865-875

Srinivasan PR, Sprinson DB (1959) 2-Keto-3-deoxy-D-arabinoheptonic acid 7-phosphate synthetase. J Biol Chem 234:716-122

Steinrucken HC, Amrhein N (1980) The herbicide glyphosphate is a potent inhibitor of 5-enolpyruvyl-shikimic acid 3-phosphate synthase. Biochem Biophys Res Commun 94:1207-1212

Stephens CM, Bauerle R (1991) Analysis of the metal requirement of 3-deoxy-D-arabino-heptulosonate-7-phosphate synthase from Escherichia coli. J Biol Chem 266:20810-20817

Stephens CM, Bauerle R (1992) Essential cysteines in 3-deoxy-Darabino-heptulosonate-7-phosphate synthase from Escherichia coli. J Biol Chem 267:5762-5767

Stephens RS, Kalman S, Lammel C, et al. (1988) Obligate intracellular pathogen of humans: Chlamydia trachomatis. Science 282:754 759

Subramaniam PS, Xie G, Xia T, Jensen RA (1998) Substrate ambiguity of 3-deoxy-D-manno-octulosonate 8-phosphate synthase from Neisseria gonorrhoeae in the context of its membership in a protein family containing a subset of 3-deoxy-D-arabino-heptulosonate 8-phosphate synthases. J Bacteriol 180:119-127

Taylor WP, Sheflyan GY, Woodard RW (2000) A single point mutation in 3-deoxy-d-manno-octulosonate 8-phosphate synthase is responsible for temperature sensitivity in a mutant strain of Salmonella typhimurium. J Biol Chem 275:32141-32146

Thompson JD, Higgins DG, Gibson TJ (1994) CLUSTAL W: Improving the sensitivity of progressive multiple sequence alignment through sequence weighting position-specific gap penalties and weight matrix choice. Nucleic Acids Res 22:4673-4680

Walsh CT, Benson TE, Kim DH, Lees WJ (1996) The versatility of phosphoenolpyruvate and its vinyl ether products in biosynthesis. Curr Biol 3:93-91

Ward CK, Lawrence ML, Veit HP, Inzana TJ (1998) Cloning and mutagenesis of a serotype-specific DNA region involved in encapsulation and virulence of Actinobacillus pleuropneumoniae serotype 5a: Concomitant expression of serotype 5a and 1 capsular polysaccharides in recombinant A. pleuropneumoniae serotype 1 . Infect Immun 66:3326-3336

White O, Eisen JA, Heidelberg JF, et al. (1999) Genome sequence of the radioresistant bacterium Deinococcus radiodurans $\mathrm{R} 1$. Science 286:1571-1577

Zhao J, Herrmann K (1992) Cloning and sequencing of a 2nd CDNAencoding 3-deoxy-d-arabino-heptulosonate 7-phosphate synthase from Solanum tuberosum L. Plant Physiol 100:1075-1076 